\title{
Brasilicardin A; a New Terpenoid Antibiotic Produced by Nocardia brasiliensis
}

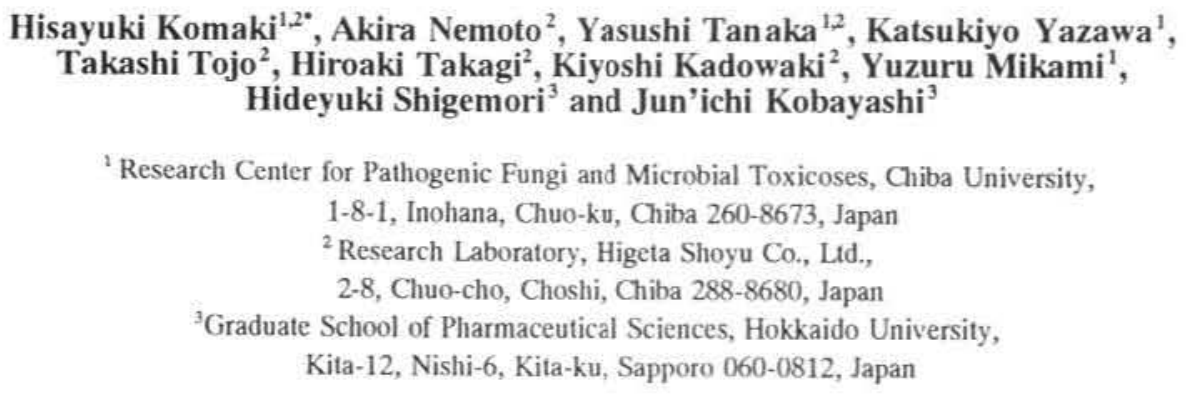

\section{(Received August 25,1998)}

Our recent search for bioactive compounds from pathogenic Nocardia resulted in the isolation of a new antibiotic, brasilicardin A, from Nocardia brasiliensis IFM 0406, a clinical isolate from a lung nocardiosis patient. Brasilicardin $\mathrm{A}$ is a novel tricyclic diterpenoid con taining an amino acid moiety, 3 -hydroxybenzoate, a rhamnose and an $N$-acetylglucosamine unit. The antibiotic exhibited immunosuppressive activity in a mouse mixed lymphocyte reaction (MLR) assay system and its $\mathrm{IC}_{50}$ value was $0.057 \mu \mathrm{g} / \mathrm{ml}$. Its immunosuppressive mechanism was considered to be different from that of the reference drug, cyclosporin $A$ (CyA), because brasilicardin A has no inhibitory activity against IL-2 production in mouse MLR assay. Also new bioactive substances which were recently isolated by our research groups from pathogenic Nocardia are reviewed.

Nocardia is an acrobic Gram-positive, filamentous and partially acid-fast bacterium which belongs to the pathogenic actinomycetes ${ }^{1)}$. Among Nocardia species, $N$. asteroides complex (N. asteroides sensu stricto, $N$. farcinica and $N$. nova), $N$. brasiliensis, $N$. otitidiscaviarum and $N$. transvalensis cause human infections ${ }^{2}$. It has been reported that the infection caused by Nocardia is uncommon, however, coupled with the increasing number of the immunocompromised patients treated with corticosteroids, AIDS and organ transplant patients, nocardiosis is thought not to be rare ${ }^{23.4}$. During the coursc of our screening program for new bioactive substances from pathogenic Nocardia, N. brasiliensis IFM 0406 was found to produce a new immunosuppressive terpenoid antibiotic named brasilicardin $\mathrm{A}$.

In this paper we report on the immunosupressive terpenoid brasilicardin A produced by $N$. brasiliensis. We also review the bioactive compounds produced by pathogenic Nocardia and reported by our research groups.

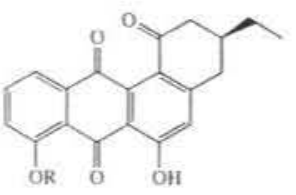

Brasiliquinones

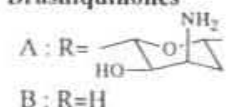

$$
\text { B: } \mathrm{R}=\mathrm{H}
$$

$\mathrm{C}: \mathrm{R}=\mathrm{CH}_{3}$<smiles>C=C(C)/C=C/C(C#N)=C/c1cn(C)c2ccccc12</smiles>

Brasilidine A<smiles>CN(CCN(C)C(CC(O)O)C(=O)O)C(CC(O)O)C(=O)O</smiles>

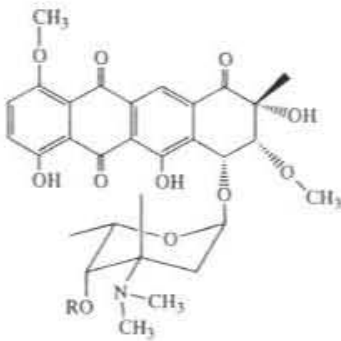

Nocardicyclins $A: \mathrm{R}=\mathrm{H}$ B : $\mathrm{R}=\mathrm{COCH}_{3}$<smiles>Cc1ccc2c(c1O)C(=O)c1c(O)c3c(c(O)c1C2=O)C[C@@](C)(O)C[C@H]3O</smiles>

EDDS

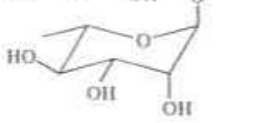
3:- $\mathrm{O}$-demethyl : $\mathrm{R}=\mathrm{CH}_{3}$ 4-O,3-O-didemethyl-: $\mathrm{R}=\mathrm{H}$
Mutactimycin derivatives

Fig. 1. Bioactive compounds produced by Nocardia. 
Table 1. List of $N$. brasiliensis strains which showed antibacterial activity.

\begin{tabular}{ccc}
\hline IFM No. & Brasilidine A & EDDS \\
\hline 0276 & + & - \\
0358 & + & - \\
0415 & + & - \\
0466 & + & - \\
0581 & + & - \\
0641 & + & - \\
0653 & + & - \\
0666 & + & - \\
0667 & + & - \\
0321 & - & + \\
0355 & - & + \\
0568 & - & + \\
0596 & - & + \\
$0326^{*}$ & - & - \\
$0370^{*}$ & - & - \\
$0378^{*}$ & - & - \\
$0381^{*}$ & - & - \\
$0383^{*}$ & - & - \\
$0386^{*}$ & - & - \\
$0407^{*}$ & - & - \\
$0493^{*}$ & - & - \\
$0642^{*}$ & - & - \\
\hline Total & $9 / 22$ & $4 / 22$ \\
\hline The chemical nature of these biosctive compound(s) \\
was not determined. \\
\hline
\end{tabular}

\section{Bioactive compounds produced by Nocardia}

Bioactive compounds obtained through our screening of pathogenic Nocardia are shown in Fig. 1. N. brasiliensis IFM 0089 produced new cytotoxic antibiotics named brasiliquinones $\mathrm{A}-\mathrm{C}$ and brasilidine $\mathrm{A}^{5 ., 7}$. Brasiliquinones are unique benz $[a]$ anthraquinone antibiotics with an ethyl group at $\mathrm{C}-3$. Furthermore, brasiliquinone $\mathrm{A}$ is the first antibiotic discovered possessing ristosamine as a sugar moiety. Brasilidine $\mathrm{A}$ is a new indole alkaloid possessing a unique triene unit conjugated with an isonitrile group. In addition to the cytotoxic activity, brasilidine $\mathrm{A}$ has antifungal activity against Aspergillus niger. N. brasiliensis IFM 0321 produced a chelating compound, $N, N^{\prime}$-ethylenediaminedisuccinic acid (EDDS). Although EDDS itself was al ready reported to be a microbial product with phospholipase C inhibitory activity ${ }^{8)}$, we could demonstrate its antimicrobial activity against bacteria and fungi such as Bacillus subtilis and Cryptococcus neoformans ${ }^{9}$.

In 1996 Ruimy et al. proposed a new taxon, $N$. pseudobrasiliensis ${ }^{10)}$. New anthracycline antibiotics named nocardicyclins $\mathrm{A}$ and $\mathrm{B}$ were isolated from the type strain, $N$. pseudobrasiliensis IFM 0624, whose structures were characterized by 1 - and 8 -methoxy groups, a 10-carbonyl group and a novel carbonmethylated aminosugar constituent called brasilinose ${ }^{11)}$. Nocardicyclin A exhibited potent antitumor activity in vitro and in vivo, and the antibiotic was less toxic than other anthracycline group antibiotics such as adriamycin. The $\mathrm{LD}_{5_{0}}$ value of nocardicyclin A was $>100 \mathrm{mg} / \mathrm{kg}$ (i.p.) in mice ${ }^{12}$. Other new anthracycline antibiotics were also obtained from $N$. transvalensis IFM 0456 strain which was isolated from AIDS patient in Thailand. They were 3 '-O-demethylmutactimycin and 4-O, 3'-O-didemethyl-mutactimycin ${ }^{133}$.

Since the most of present bioactive substances were produced by strains of $N$. brasiliensis, we were interested in the productivity of antimicrobial substance by clinical isolates of $N$. brasiliensis. Our survey on the productivity of 76 clinical isolates of N. brasiliensis showed that antimicrobial substances were produced in methanol extracts of 18 strains and culture filtrates of 4 strains (Table 1). Among 22 strains with antimicrobial activity, 9 strains were found to produce brasilidine A. Four strains with antimicrobial activity were found to be producers of $\operatorname{EDDS}^{9}$. However the chemical nature of the compounds in the remaining 9 extracts was not determined.

These studies suggest the potential usefulness of pathogenic Nocardia as sources of new bioative substances, although much attention should be paid to handling of these pathogenic Nocardia since pathogenic Nocardia belongs to class the 2 category in biohazard ranks.

\section{A new immunosuppressive terpenoid,} brasilicardin A

Strain IFM 0406, which was tentatively identified as Nocardia sp., was found to produce immunossupressive agents in our screening using mouse MLR assay system. The mycelium of the IFM 0406 strain was rudimentary branched, and primitive aerial mycelia were observed. Long time cultivation made the mycelium fragment into bacillary clements. The analysis of cell wall hydrolysates 


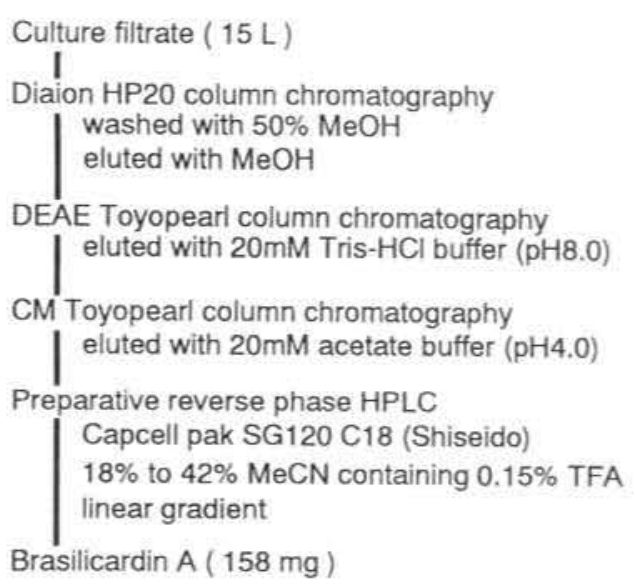

Fig. 2. Purification scheme of brasilicardin A.

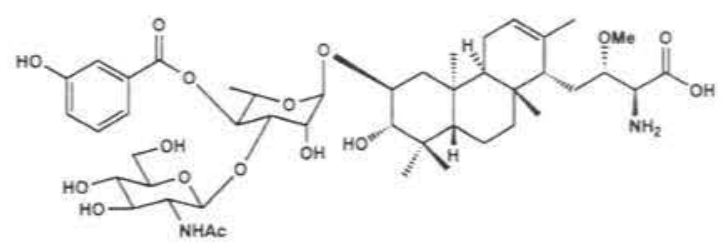

Fig. 3. Chemical structure of brasilicardin A.

revealed the presence of meso-diaminopimelic acid, and arabinose and galactose as major sugar constituents. Therefore, the cell wall type was considered to belong to chemotype $\mathrm{IV}^{1)}$. The analysis of mycolic acid showed the presence of Nocardia or Rhodococcus type one. Menaquinone composition of this strain was $\mathrm{MK}-8 \mathrm{H}_{4}$ (cycle) as the major and $\mathrm{MK}-8 \mathrm{H}_{2}$ and $\mathrm{MK}-9 \mathrm{H}_{4}$ as minor. Casein, hypoxanthine and tyrosine were decomposed, and acid was produced from galactose and inositol. These characteristics and the results of the susceptibility tests to antimicrobial agents ${ }^{14}$ suggested that strain IFM 0406 belongs to $N$. brasiliensis $^{15)}$.

When the time course of the brasilicardin A production during the cultivation in a 20 liter jar fermenter was monitored, the production was found to begin at the middle to late log-phase and it reached a maximum at 70 to 80 hours cultivation. At this time, about $60 \mathrm{mg}$ /liter of brasilicardin A was produced in culture filtrate.

The purification procedure of brasilicardin A is summarized in Fig. 2. From 15 liter culture filtrate, $158 \mathrm{mg}$ of brasilicardin A was purified by successive chromatography.

The physico-chemical properties of brasilicardin A are summarized in Table 2. Structure elucidation was established on the basis of spectroscopic data, chemical means and X-ray analysis. Brasilicardin A is a tricyclic diterpenoid antibiotic containing an amino acid moiety, 3-hydroxybenzoate, a rhamnose and an $\mathrm{N}$-acetylglucosamine unit (Fig. 3). Detailed structural studes are reported elsewhere ${ }^{16}$. Only a few terpenoid compounds have been reported as secondary metabolites from actinomycetes, although a wide variety of terpenoid compounds are produced by fungi and plants. To our knowledge, this is the first report of the natural product containing such anti/syn/antiperhydrophenanthrene structure from actinomycetes.

Biological activities of brasilicardin A were studied. The effect of brasilicardin A on mouse MLR was examined in comparison with that of CyA. Brasilicardin A showed suppressive activity against the proliferative response of mouse lymphocytes to alloantigen stimulation. The $\mathrm{IC}_{50}$ values of brasilicardin $\mathrm{A}$ and $\mathrm{CyA}$ on mouse MLR were 0.057 and $0.15 \mu \mathrm{g} / \mathrm{ml}$, respectively. CyA is widely used as an immunosuppressive agents for clinical organ transplantation ${ }^{17}$. It has been reported that CyA inhibits the IL-2 production from $\mathrm{T}$ helper cells, and the inhibition triggers suppression of the immune system, such as allograft rejection, by blocking T-cell activation ${ }^{10}$. To determine whether the suppressive activity of brasilicardin $\mathrm{A}$ is due to inhibition of the IL-2 production, the effects of brasilicardin A and CyA on IL-2 production in mouse MLR were studied. CyA inhibited the IL-2 production in dose-depended manner, however, the inhibition was not confirmed with brasilicardin $A$. These results indicate brasilicardin $A$ has a different immunosuppressive mechanism from that of CyA.

The effects of brasilicardin A on the growth of human cultured cell lines in vitro were tested using Jurkat, Molt4, CCRF-CEM, HeLa and HEK293. Brasilicardin A exhibited relatively higher $I_{50}$ values for various cell lines, and the $I_{50}$ values for these cultured cell lines were more than 100 times greater than that for mouse MLR. In vivo toxicity test using mice indicated that single intravenous administration of 
Table 2. Physico-chemical properties of brasilicardin A.

\begin{tabular}{ll}
\hline Appearance & White powder \\
Molecular weight & 892 \\
Molecular formula & $\mathrm{C}_{45} \mathrm{H}_{68} \mathrm{~N}_{2} \mathrm{O}_{16}$ \\
HRFAB-MS(m/z) & \\
$\quad$ Found & $893.4646(\mathrm{M}+\mathrm{H})^{+}$ \\
$\quad$ Calcd. & $893.4647\left(\right.$ for $\left.\mathrm{C}_{45} \mathrm{H}_{69} \mathrm{~N}_{2} \mathrm{O}_{16}\right)$ \\
{$[\alpha]_{\mathrm{D}}^{30}$} & $+15.0^{\circ}(c 0.5, \mathrm{MeOH})$ \\
$\mathrm{IR}(\mathrm{KBr}) \nu \max \left(\mathrm{cm}^{-1}\right)$ & $3432,2934,1676,1454,1378,1291,1203,1075$, \\
& $893,839,801,755,722,570$ \\
$\mathrm{UV}(\mathrm{MeOH}) \lambda_{\max }$ & $212(\varepsilon 15000), 239(\varepsilon 5200), 300(\varepsilon 1900) \mathrm{nm}$ \\
Solubility & Soluble $: \mathrm{H}_{2} \mathrm{O}, \mathrm{MeOH}_{\mathrm{m}} \mathrm{EtOH}$ \\
& Insoluble : $\mathrm{CHCl}, \mathrm{EtOAc}, \mathrm{Me}_{2} \mathrm{CO}$, diethyl ether \\
\hline
\end{tabular}

brasilicardin A showed no sign of toxicity at a dose of $100 \mathrm{mg} / \mathrm{kg}$ (manuscript in preparation).

Thus, brasilicardin A produced by $N$. brasiliensis IFM 0406 is a novel terpenoid immunosuppresssant with low toxicity in vitro and in vivo. Therefore, it is anticipated that brasilicardin A may be worthy of investigations in clinical application as a useful immunosuppressive agent.

\section{REFERENCES}

1) Goodfellow, M. : The family Nocardiaceae. In "The Prokaryotes, 2nd ed." (ed. A. Balows et al.), pp 1188-1213, Springier Verlag, Berlin, 1992.

2) Beaman, B. L. \& L. Beaman : Nocardia species Host-parasite relationships. Clin. Microbiol. Rev. $7: 213-264,1994$

3) Schiff, T. A.; M. Sanchez, J. Moy, D. Krilsfeld, M. F. McNeil \& J. M. Brown : Cutaneous nocardios is caused by Nocardia nova occurring in an HIV infected individual: A case report and review of the literature. AIDS 6: 849-954, 1993.

4) Poowan, N.; M. Kusum, Y. Mikami, K. Yazawa, Y. Tanaka, T. Gonoi, S. Hasegawa \& K. Konyama : Pathogenic Nocardia isolated from clinical specimens including those of AIDS patients in Thailand. Eur. J. Epidem. 11: 507 . $512,1995$.

5) Nemoto, A.; Y. Tanaka, Y. Karasaki, H. Komaki K. Yazawa, Y. Mikami, T. Tojo, K. Kadowaki, M Tsuda \& J. Kobayashi : Brasiliquinones A, B and $C$, new benz $[a]$ anthraquinone antibiotics from Nocardia brasiliensis 1. Producing strain, isolation and biological activities of the antibiotics J. Antibiotics 50: 18-21, 1997.

6) Tsuda, M.; H. Sato, Y. Tanaka, K. Yazawa Y Mikami, T. Sasaki \& J. Kobayashi : Brasiliquinones A-C, new cytotoxic benzla anthra- quinone with an ethyl group at C-3 from actinomycete Nocardia brasiliensis. J. Chem. Soc., Perkins Trans. 1: 1773-1775, 1996.

7) Kobayashi, J. ; M. Tsuda, A. Nemoto, Y. Tanaka, K. Yazawa \& Y. Mikami : Brasilidine A, a new cytotoxic isonitrile-containing indole alkaloid from the actinomycete Nocardia brasiliensis. J. Nat. Prod. 60 : 719-720, 1997.

8) Nishikawa, $T$; A. Okuyama, H. Naganawa $T$. Takita, M. Hamada, T. Takeuchi, T. Aoyagi \& H. Umezawa : Production by actinomycetes of N,N'. ethylenediaminedisuccinic acid, an inhibitor of phospholipase C. J. Antibiotics 37 : 426-427, 1984.

9) Imai, T. ; K. Yazawa, Y. Tanaka, Y. Mikami, T. Kudo, K. Suzuki, A. Ando, Y. Nagata \& U Gracfe : Productivity of antimicrobial substance in pathogenic actinomycetes Nocardia brasiliensis. Microbiol. Cult. Coll. 13: 103-108, 1997.

10) Ruimy, R.; P. Riegel, A. Carlotti, P. Boiron, G. Bernardin \& R. J. Wallace Jr. : Nocardia pseudobrasiliensis sp. nov , a new species of Nocardia which groups bacterial strains previously identified as Nocardia brasiliensis and associated with invasive diseases. Int. J. Syst. Bacteriol. 46 : 259-264,1996.

11) Tanaka, Y.; U. Graefe, K. Yazawa, Y. Mikami \& M. Ritzau : Nocardicyclins A and B : new anthracycline antibiotics produced by Nocardia pseudobrasiliensis. J. Antibiotics 50 : 822-827, 1997.

12) Tanaka, Y.; U. Graefe, K. Yazawa \& Y. Mikami. : Production of nocardicyclins by clinical isolates of Nocardia pseudobrasiliensis and in vitro antitumor activity of the antibiotics. J. Antibiotics 51 : 589-591, 1998.

13)Speitling, M. : N. Poonwan, K. Yazawa Y. Mikami, 1. Grun-Wollny. M. Ritzau, H. Laatsch \& U. Graefe : Demethyl mutactimycins, new 
anthracycline antibiotics from Nocardia and Streptomyces strains. J. Antibiotics, 51: 693-698, 1998.

14) Mikami, Y. \& K. Yazawa : Susceptibility patterns of pathogenic Nocardia to some selected antimicrobial agent and their usefulness in the identification work in a clinical laboratory. Bulletin of the Japan Federation for Culture Collections 5 : 89-95, 1989.

15) Tanaka, Y.; H. Komaki, K. Yazawa, Y. Mikami A. Nemoto, T. Tojyo, K. Kadowaki, H. Shigemori \& J. Kobayashi : Brasilinolide A, a new macrolide antibiotic produced by Nocardia brasiliensis : producing strain, isolation and biological activity. J. Antibiotics 50 : 1036-1041, 1997.

16) Shigemori, H.; H. Komaki, K. Yazawa, Y.
Mikami, A. Nemoto, Y. Tanaka, T. Sasaki, Y. In, T. Ishida \& J. Kobayashi: Brasilicardin A, a novel tricyclic metabolite with potent immunosupressive activity from actinomycete Nocardia brasiliensis. J. Org. Chem. 63: 69006904, 1998.

17) Borel, J. F. : History of cyclosporin A and its significance in immunology. In "Cyclosporin $A$ " (ed. J. F. Borel), pp. 5-17, Elsevier Biochemical Press, Amsterdam, 1982.

18) Liu, J. ; J. D. Farmer Jr., W. S. Lane, J. Freedman, 1. Weissman \& S. L. Schreiber : Calcineurin is a common target of cyclophilin-cyclosporin $\mathrm{A}$ and FKBP-FK506 complexes. Cell 66:807-815, 1991. 